\title{
Welding procedure research of titanium heat exchangers
}

\author{
Jiang Chengjun ${ }^{1 a^{*}}$, Wang Wei ${ }^{1 b}$, Li Qian ${ }^{1 \mathrm{c}}$, Zhang Xiaoli² \\ ${ }^{1}$ Shanghai Institute of Special Equipment Inspection \& Technical Research, Putuo, Shanghai, China \\ ${ }^{2}$ Shanghai Morimatsu Pressure Vessel Co., Ltd, Pu Dong, Shanghai, China
}

\begin{abstract}
In order to manufacture Gr.1 titanium heat exchangers, the welding property and weld structure of titanium tube-to-tubesheet are analyzed. The procedure of Pulse GTAW is used and the visual inspection, dimensional inspection, chemical composition, mechanical properties and metallographic structures are tested and analyzed. The results show that the weld joint can get ideal structure and good chemical composition, mechanical properties and corrosion resistance. The successful welding qualification has accumulated valuable experience for manufacture of titanium heat exchangers.
\end{abstract}

\section{Induction}

A pressure vessels order for purified terephthalic acid (PTA) plant have been received by a company in Shanghai. SB338 Gr.1 titanium tubes and SA266 Gr.2+ SB265 Gr.1 composite materials are used in design of the heat exchanger tube side. Gr.1 titanium tube is ASME SB338 material (equivalent to TA1 according to GB/T 3625-2007 in China), Gr.1 titanium plate in the composite material is ASME SB265 material (equivalent to TA1 according to GB/T 3621-2007 in China). SA266 Gr.2 in the composite material is a carbon steel forging material for pressure vessel components, which is connected SB338 Gr.1 titanium tubes by expansion and no welding.

In accordance with the code of TSG 21'Supervision Regulation on Safety Technology for Stationary Pressure Vessels' and the product standard of JB/T 4745 'titanium welded vessels', the welding procedure qualification for the tube-to-tubesheet should be tested to determine the appropriate welding procedure parameters before the manufacturing work of the first pressure vessel.

\section{Welding property of titanium tube-to- tubesheet}

Gr.1 titanium is a pure metal with a bright white luster and a very low content of impurities. Gr.1 Titanium is easy to react with air at high temperature. With the increase of temperature, it has reacted with hydrogen, oxygen and nitrogen successively ${ }^{[1]}$. Therefore, the measure of protective gas should be taken first to avoid pollution in the welding process. Gr.1 Titanium has the advantages of high specific strength, high temperature creep resistance and corrosion resistance, etc. It is mainly used in engineering with harsh environment, such as aerospace, petrochemical, seawater desalination and nuclear power plant and other fields.
Titanium has a high melting point of $1668^{\circ} \mathrm{C}$ and poor thermal conductivity, which leads to a long residence time at high temperature in the weld metal. That will be easy to cause coarse grains, which affects the mechanical properties and corrosion resistance of the joint ${ }^{[2]}$. During welding, it is necessary to control the heat input to avoid coarse grains in the heat-affected zone. The Welding of Gr.1 titanium is easy to produce small and a lot of pores. This is mainly because hydrogen in the weld metal is not easy to diffuse and escape with the solubility of hydrogen goes down during the cooling process of the weld metal. Then hydrogen will gather together to form pores. What's more, cracks may be appeared in the weld metal after a period of time after welding. Therefore, the appropriate welding heat input must be chosen to ensure the weld quality.

\section{Design of welding procedure test}

\subsection{Welding method}

There are many welding methods suitable for titanium and titanium alloy, such as gas tungsten arc welding (GTAW), vacuum electron beam welding, plasma welding, laser welding and other high-energy particle beam welding ${ }^{[3]}$. Due to the thin thickness of Gr.1 titanium tube, welding burn-off and deformation caused by excessive melting amount of titanium material are likely to occur in the welding process. In order to obtain the weld joint with the requirement of penetration depth and small grain size, according to the part size, structural characteristics and welding conditions, the method of GTAW is adopted to carry out welding test on the tube-to-tubesheet of titanium heat exchanger.

In order to ensure the weld root penetration and the back of the weld forming well, the pulsed GTAW method is chosen in this tube-to-tubesheet welding ${ }^{[4]}$. The current amplitude or effective value of the pulsed GTAW method

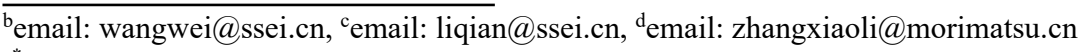

$\mathrm{a}^{*}$ Corresponding author's e-mail: jiangcj@ssei.cn 
varies periodically at a certain frequency. The welding sample is heated and melted to form a point molten pool when each pulse current passes through, and the welding pool condenses, crystallizes and maintains arc combustion when the base current passes through. Thus, the welding process is an intermittent heating process in which the weld joint is formed by one point molten pool after another superimposed point pool. The greatest advantage of pulsed GTAW method is reducing the heat input to the tube-totubesheet. The amount of heat input can be easily adjusted at the pulse current and pulse time as well as the base current and holding time, which is beneficial to controlling the depth of weld pool and back form of weld seam.

\subsection{Welding structure design of tube-to- tubesheet}

There are three main welding structure used for tube-totubesheet: external convex type, internal concave type and flush type ${ }^{[5]}$. External convex type is little affected by the construction conditions, but the strength is not high and easy to be eroded; Internal concave type has small erosion and the structure is beautiful, but the fillet weld strength is low and there is the risk of tube shrinkage; Flush type can maximize the weld strength, and the structure is beautiful. The tube-to-tubesheet weld joints are the weak points in heat exchangers by analyzing the causes for leakage of the heat exchanger system. Low weld strength is the main reason. Therefore, the structure of the tube-to-tubesheet is designed as the flush type to effectively improve the service life of heat exchanger system, as shown in Fig.1.

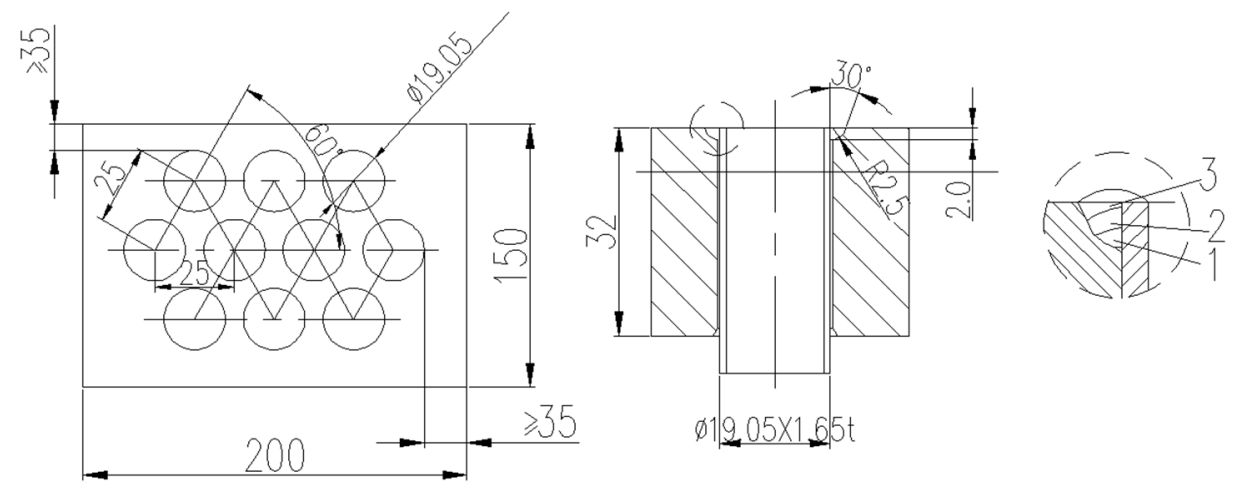

Fig.1 Sketch map for the aligned welding sample

It is difficult to protect the back side of titanium tubeto-tubesheet during welding. So inert gas protection tool or special process should be adopted to ensure that the high temperature zone of welding is not oxidized. The manufacture method of tube-to-tubesheet expansion before welding is adopted to facilitate heat conduction, weld joint forming and prevent oxidation of the weld back side. The root layer is self-fused without welding wire to form a good molten pool, as shown in Fig.2.



\subsection{Test materials}

The material specifications of the titanium heat exchanger are as follows: SB338 Gr.1 titanium tubes are OD $19.05 \mathrm{~mm} \times 1.65 \mathrm{~mm}$; SA266 Gr.2+ SB265 Gr.1 composite tubesheet is $30+2 \mathrm{~mm}$; the welding material is ERTi-2 titanium wires with diameter of $0.8 \mathrm{~mm}$ according to AWS A5.16. The chemical composition of Gr.1 titanium tube, Gr.1 titanium plate in composite tubesheet and ERTi-2 wires used in the test are shown in Tab.1. The mechanical properties of the test materials are shown in Tab.2.

Fig.2 Sketch map for welding root layer

Tab.1 Chemical composition of the test materials (\%)

\begin{tabular}{|c|c|c|c|c|c|c|c|c|}
\hline Elements & $\mathrm{Ti}$ & $\mathrm{Fe}$ & $\mathrm{C}$ & $\mathrm{N}$ & $\mathrm{O}$ & $\begin{array}{c}\text { H } \\
\text { Other } \\
\text { elements } \\
\text { max. each }\end{array}$ & $\begin{array}{c}\text { Other } \\
\text { elements } \\
\text { max. total }\end{array}$ \\
\hline $\begin{array}{c}\text { SB338 Gr.1 } \\
\text { titanium tube }\end{array}$ & remainder & 0.18 & 0.08 & 0.02 & 0.14 & 0.013 & 0.09 \\
\hline $\begin{array}{c}\text { SB265 Gr.1 } \\
\text { titanium plate }\end{array}$ & remainder & 0.15 & 0.06 & 0.01 & 0.17 & 0.015 & 0.32 \\
\hline Welding wire & remainder & 0.10 & 0.05 & 0.009 & 0.11 & 0.009 & 0.08 \\
\hline
\end{tabular}


Tab.2 Mechanical properties of the test materials

\begin{tabular}{|c|c|c|c|}
\hline \multirow{2}{*}{ Materials } & \multicolumn{3}{|c|}{ Mechanical properties } \\
\cline { 2 - 4 } & $\begin{array}{c}\text { Yield Strength } \\
\mathrm{R}_{\mathrm{P} 0.2}(\mathrm{MPa})\end{array}$ & $\begin{array}{c}\text { Tensile Strength } \\
\mathrm{R}_{\mathrm{m}}(\mathrm{MPa})\end{array}$ & $\begin{array}{c}\text { Elongation } \\
\delta(\%)\end{array}$ \\
\hline SB338 Gr.1 titanium tube & 303 & 378 & 42.5 \\
\hline SB265 Gr.1 titanium plate & 288 & 415 & 38 \\
\hline Welding wire & 321 & 407 & 34 \\
\hline
\end{tabular}

\subsection{Welding procedure parameters}

When Gr.1 titanium tube-to-tubesheet is welded, measures should be taken to make the heat transfer conditions of tubes and tubesheet close to each other, and the welding arc position should be controlled. During welding, copper bars should be placed in the tubes as shown in Fig.2 to accelerate cooling and prevent oxidation of titanium tube. Specific welding procedure conditions are shown in Tab.3.

Tab.3 Welding parameters of Gr.1 titanium tube-to-tubesheet

\begin{tabular}{|c|c|c|c|c|c|c|c|c|c|}
\hline \multirow{2}{*}{$\begin{array}{l}\text { Welding } \\
\text { position }\end{array}$} & \multirow{2}{*}{$\begin{array}{c}\text { Polarity } \\
\text { of } \\
\text { power }\end{array}$} & \multicolumn{3}{|c|}{$\begin{array}{c}\text { Strike } \\
\text { current }\end{array}$} & $\begin{array}{c}\text { Highest } \\
\text { Current }\end{array}$ & $\begin{array}{c}\text { Base } \\
\text { current }\end{array}$ & $\begin{array}{c}\text { Ooltage } \\
(\mathrm{V})\end{array}$ & \multirow{2}{*}{$\begin{array}{c}\text { Speed } \\
(\mathrm{cm} / \mathrm{min})\end{array}$} & \multicolumn{2}{|c|}{ Shielding gas } & Type & $\begin{array}{c}\text { Flow rater-pass } \\
(\mathrm{L} / \mathrm{min})\end{array}$ & $\begin{array}{c}\text { Intemp. } \\
\left({ }^{\circ} \mathrm{C}\right)\end{array}$ \\
\hline $5 \mathrm{FGG}$ & DCEN & $50 \sim 54$ & $75 \sim 80$ & $25 \sim 28$ & $10 \sim 12$ & $24 \sim 2$ & $\geq 99.999 \% \mathrm{Ar}$ & $16 \sim 20$ & $\leq 150$ \\
\hline
\end{tabular}

\subsection{Welding protection}

Gr.1 titanium is a highly active metal, which can absorb a lot of oxygen, nitrogen and hydrogen above $250^{\circ} \mathrm{C}$. Hydrogen, oxygen, nitrogen and titanium form brittle compounds, which not only decrease the plasticity and toughness, but also sharply decrease the corrosion resistance $^{[6]}$. Therefore, it is particularly important to strengthen the inert gas protection before welding and during welding.

Before welding, the Gr.1 titanium tubes and tubesheet should be mechanical cleaning. The oxide films in the tubesheet surface and grooves are clean up by stainless steel wire brush, then emery papers are used to grind the surface and grooves. At last, oil, dirt, and other residual metal pollutants should be clean up by acetone or alcohol and blow-dry using the cooling fan.

During welding, the protection of the weld joint mainly depends on protection gas of the welding torch. The back protection of the weld seam depends on the method of expansion before welding. The protective gas is argon with purity greater than $99.999 \%$ and dew point lower than $-40^{\circ} \mathrm{C}$. The welding torch device is equipped with multi-layer copper wire mesh to prevent turbulence and ensure smooth gas distribution. The inert gas delivery pipe is made of clean polyethylene pipe. In order to make the air in the delivery pipe removed and air in the protection area completely replaced, the welding torch should be ventilated in advance. After welding, hysteretic gas shutdown should be adopted until the temperature of the weld seam and its surrounding base metal drops to $250^{\circ} \mathrm{C}$.

\section{Qualification test of the welding sample}

\subsection{Visual inspection and penetrant test}

The weld joint of Gr.1 titanium is silvery white without air pollution, golden yellow with slight air pollution, blue with moderate air pollution and gray with severe air pollution. Serious oxidation pollution of Gr.1 titanium weld joint will lead to material embrittlement. The extent of oxidation pollution after welding can be judged by inspecting the different color characteristics presented. The following procedures can only be carried out after passing the layer color requirements. In the welding test sample by GTAW procedure, the surface of weld seam, the base metal near the seam and most of the heat-affected zone is silver white, and only a small part of the heataffected zone is golden yellow. The appearance quality of the weld joint is good and satisfy the standard requirements. The inside and outside weld joint of the tube-to-tubesheet are smooth and have no welding defects such as surface pores, slag inclusion, corner angles and grooves, as shown in Fig.3. The weld surface is inspected by $100 \% \mathrm{PT}$, and there is no linear display. The PT result satisfies level I of the standard NB/T47013.5-2015.

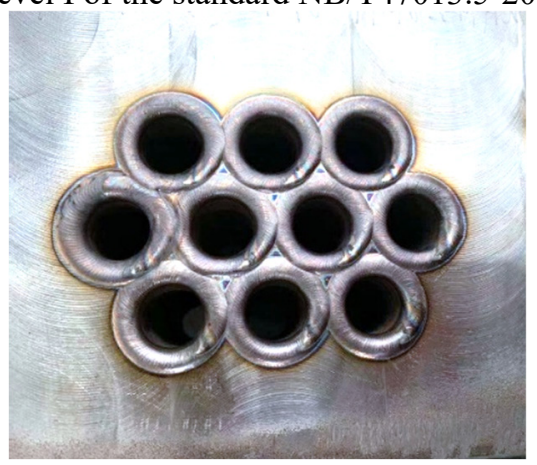

Fig.3 Weld joint appearance of the tube-to-tubesheet sample 


\subsection{Macroscopic examination and dimensional inspection}

Four weld joints of the tube-to-tubesheet sample are randomly selected to take cross-section specimens for macroscopic examination. No cracks or pores are found in the specimens by visual inspection and 10-fold magnifying glass, as shown in Fig.4. Under the action of welding stress, the tube may be deformed and shrink in diameter, so the size should be measured and not exceed the specified value $\pm 10 \%$ OD. The diameters of the tube orifices are measured with the appropriate plug gauge, and the result is in the range of the specified value. At the same time, the welding throat sizes of the joint samples are measured. According to the design requirements, the average welding throat size should be at least 0.9 times of the tube thickness $(1.485 \mathrm{~mm})$. The welding throat thickness of the measured surfaces are all higher than the specified value, and the average welding throat size is $1.796 \mathrm{~mm}$, as shown in Tab.4.

Tab.4 Welding throat thickness of the joints (mm)

\begin{tabular}{|c|c|c|c|c|c|c|c|c|}
\hline $\begin{array}{c}\text { Tube orifice } \\
\text { No. }\end{array}$ & \multicolumn{3}{|c|}{1} & \multicolumn{5}{c|}{2} \\
\hline $\begin{array}{c}\text { Cross-section } \\
\text { No. }\end{array}$ & 1 & 2 & 3 & 4 & 1 & 2 & 3 & 4 \\
\hline $\begin{array}{c}\text { Welding throat } \\
\text { thickness }\end{array}$ & 1.95 & 1.77 & 1.72 & 1.82 & 1.76 & 1.84 & 1.78 & 1.73 \\
\hline
\end{tabular}



Fig.4 Morphology of the cross-section sample

\subsection{Chemical composition analysis of the weld joints}

Samples are taken from the weld zone of the joints for $\mathrm{N}$, $\mathrm{H}$ and $\mathrm{O}$ impurities analysis. The content of $\mathrm{N}, \mathrm{H}$ and $\mathrm{O}$ impurities in the weld metal are analyzed by ELTRA ONH2000 gas analyzer. The results are shown in Tab.5. The contents of N, H and $\mathrm{O}$ impurities in the weld metal are very low. Although there is a tendency of oxygen absorption, their contents are not more than the upper limit of the materials. The results show that the protection effect of the welding process is good and the content of impurities in the weld joints can be effectively controlled.

Tab.5 Impurity elements analysis of the weld metal (\%)

\begin{tabular}{|c|c|c|c|}
\hline \multirow{2}{*}{$\begin{array}{c}\text { Sample } \\
\text { No. }\end{array}$} & \multicolumn{3}{|c|}{ Impurity elements } \\
\cline { 2 - 4 } & $\mathrm{N}$ & $\mathrm{H}$ & $\mathrm{O}$ \\
\hline $1 \#$ & 0.029 & 0.012 & 0.17 \\
\hline $2 \#$ & 0.021 & 0.013 & 0.18 \\
\hline
\end{tabular}

\subsection{Hardness test and Tensile test}

The digital Vickers hardness tester with the type of HVS50 is used to test the hardness of each zone in a randomly selected weld joint, as shown in Tab.6. The test results show that the weld seam has the highest hardness and the base metal has the lowest hardness. The reason is that due to the influence of heat input, a small amount of Martensite appeared in the weld seam, which made the microstructure of the weld seam coarse and the hardness of the weld seam increased.

Tab.6 Hardness test results (HV10)

\begin{tabular}{|c|c|c|c|c|c|c|}
\hline Test site & Base metal $^{1}$ & $\begin{array}{c}\text { Heat-affected } \\
\text { zone }^{1}\end{array}$ & Weld seam & $\begin{array}{c}\text { Heat-affected } \\
\text { zone }^{2}\end{array}$ & Base metal $^{2}$ & Remark \\
\hline Hardness & $\begin{array}{c}171,174, \\
172\end{array}$ & $175,179,175$ & $\begin{array}{c}180,178, \\
181\end{array}$ & $176,170,169$ & $163,158,156$ & $\begin{array}{c}1: \text { tube; } \\
\text { 2: tubesheet }\end{array}$ \\
\hline
\end{tabular}

The tensile test is carried out by a WE-60 universal tester. The tensile force is kept along the axial direction of the tubes. After all the tubes are pulled off from the specimen, no cracks or necking are found in the titanium tubes. The fracture site is located in the tubes, and the tensile stress calculated satisfied the design requirements. The test results are shown in Tab.7.

Tab.7 Tensile test results

\begin{tabular}{|c|c|c|c|c|c|c|}
\hline No. & Width $(\mathrm{mm})$ & $\begin{array}{c}\text { Thickness } \\
(\mathrm{mm})\end{array}$ & Area $\left(\mathrm{mm}^{2}\right)$ & $\begin{array}{c}\text { Total load } \\
(\mathrm{KN})\end{array}$ & $\mathrm{Rm}(\mathrm{MPa})$ & $\begin{array}{c}\text { Fracture } \\
\text { site }\end{array}$ \\
\hline 1 & 19.05 & 1.65 & 98.698 & 44.39 & 449.76 & tube \\
\hline 2 & 19.05 & 1.65 & 98.698 & 41.05 & 415.92 & tube \\
\hline
\end{tabular}

\subsection{Metallographic examination}

The microstructures of the weld seam and heat-affected zone are observed by metallographic microscope, as shown in Fig.5. The microstructure of the weld seam is composed of a large number of $\beta$ phases. Although the microstructure of the heat-affected zone near the weld 
seam has a certain degree of grain coarsening, the coarsening degree is very small due to the copper bar cooling measures adopted in the welding process, so as to ensure the good microstructure of the heat-affected zone.

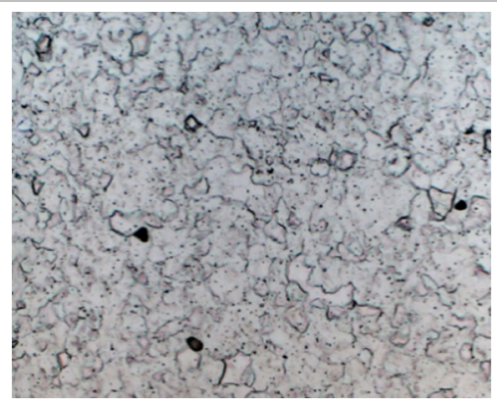

(a) base metal $\times 200$

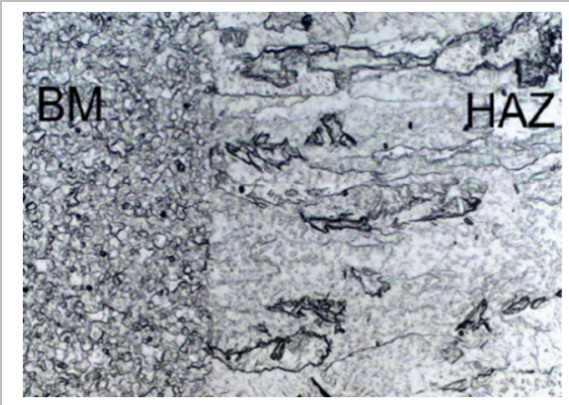

(b) heat-affected zone

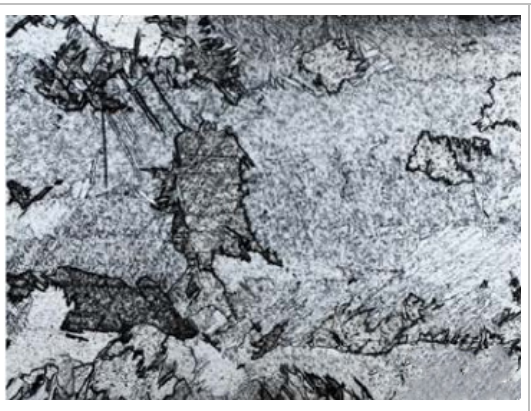

(c) weld seam

$\times 200$

Fig.5 Metallographic structures of the weld joint zones

\section{Conclusions}

Based on the above tests, the analysis conclusions are summarized as follows:

(1) Gr.1 titanium materials have moderate weldability. Using reasonable procedure parameters and high-purity argon to take strict protection, good pollution-free weld joints can be obtained.

(2) When the pulse GTAW procedure is used in Gr.1 titanium tube-to-tubesheet welding, it forms the good weld joint with ideal microstructures, good mechanical properties and corrosion resistance.

In the welding of $\mathrm{MC}$ air lift reboiler, kettle reboiler of TEA recovery tower pressure vessels for PTA plant, the above technology and procedure is adopted. The inspection results satisfy the code and design requirements. The successful welding qualification has accumulated valuable experience for manufacture of titanium heat exchangers.

\section{References}

1. Welding Institute of China Mechanical Engineering Association. (2008) Welding handbook. China Machine Press, Beijing.

2. Corscia, M. (1996) Titanium and titanium materials for the Pharmaceutical Industry. Titanium Press Monitor, 235: 192-206.

3. Zhu, G.Q. (2012) Manufacturing technology for titanium composite plate equipment. Petrochemical equipment, 1: 68-70.

4. Ai, J.L., Yang Y.F., Jiao D.B. (2001) Effect of cladding thickness on weldability of titanium-steel composite plates. Welding technology, 30: 5-6.

5. Huang, B.Y., Li, C.G. (2005) Welding manual for nonferrous materials. Chemical Industry Press, Beijing.

6. Xin W., Ye J.L. (2011) Study on welding process of titanium cladding for titanium steel composite plates. Progress in titanium Industry, 28: 38-40. 